\title{
ULTRASOUND GUIDED ERECTOR SPINAE PLANE BLOCK FOR SURGICAL ANESTHESIA IN POSTERIOR THORACIC LIPOMA EXCISION: A CASE REPORT
}

\section{Onur Balaban and Tayfun Aydın}

\author{
M.D. Kutahya Health Sciences University Hospital, Department of Anesthesiology and Pain, Kutahya, \\ Turkey.
}

Background. Ultrasound guided erector spinae plane block (ESP) has been recently reported as an effective method for surgical anesthesia in minor surgery. ${ }^{1-4}$ We aim to present a case of lipoma excision from the posterior thoracic wall, operated under ESP block.

Method: Written informed consent was obtained from the patient. The patient was 38-year-old female who had a mass located at left posterior thoracic wall, $5 \mathrm{~cm}$ lateral to the neuraxial midline between T3 and T5 skin dermatomes (Figure 1).

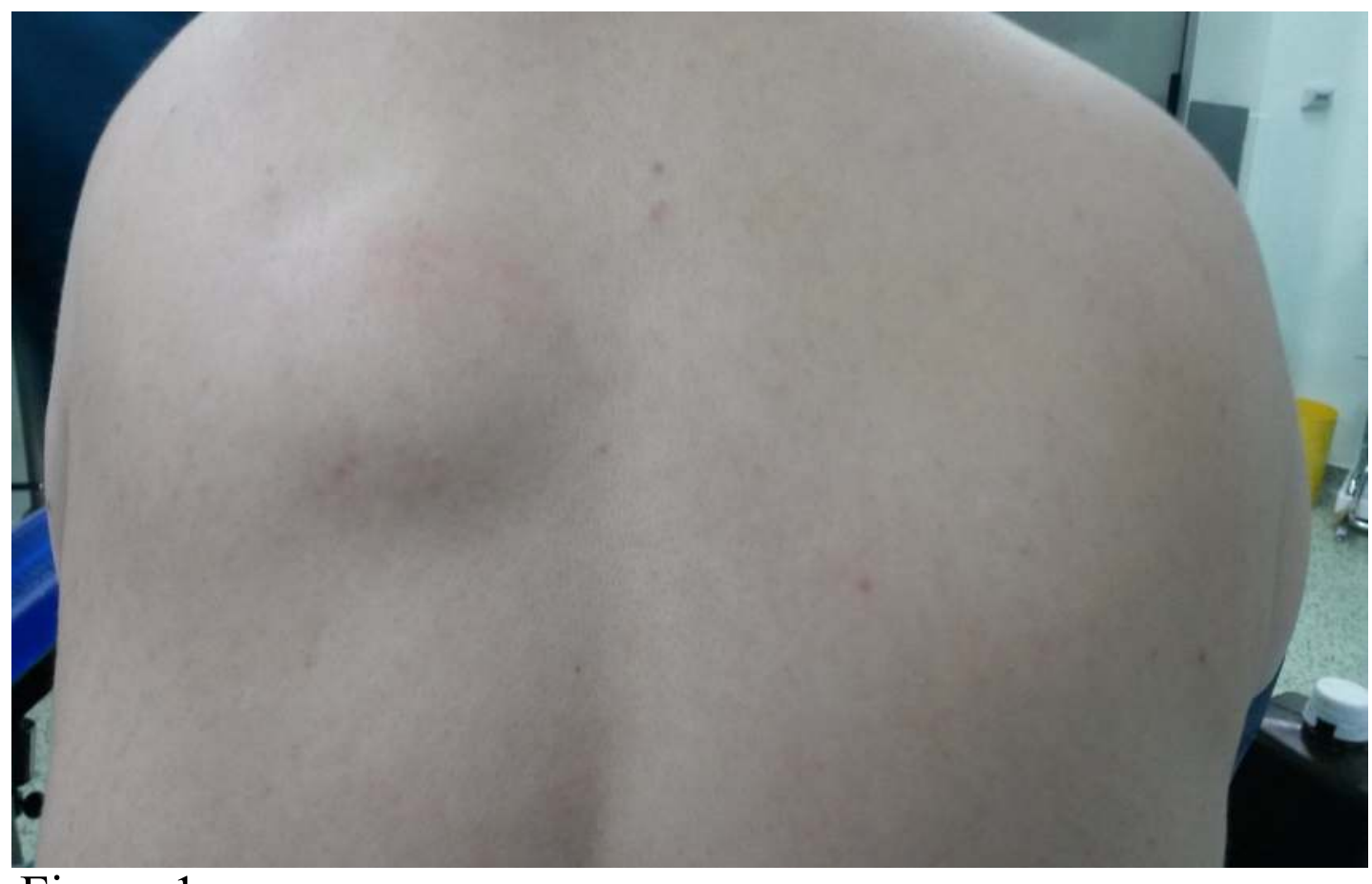

Figure 1

The patient was sedated with $2 \mathrm{mg}$ midazolam. We performed ultrasound (US) guided erector spinae plane block at T4 dermatome in sitting position using a high frequency ultrasound probe. We administered $35 \mathrm{ml}$ local anesthetic drug mixture $(20 \mathrm{ml} \quad 0.5 \%$ Marcaine $+5 \mathrm{ml} 2 \%$ Lidocaine $+10 \mathrm{ml}$ normal saline) between the $\mathrm{T} 4$ transverse process and erector spinae muscle (Figure 2).

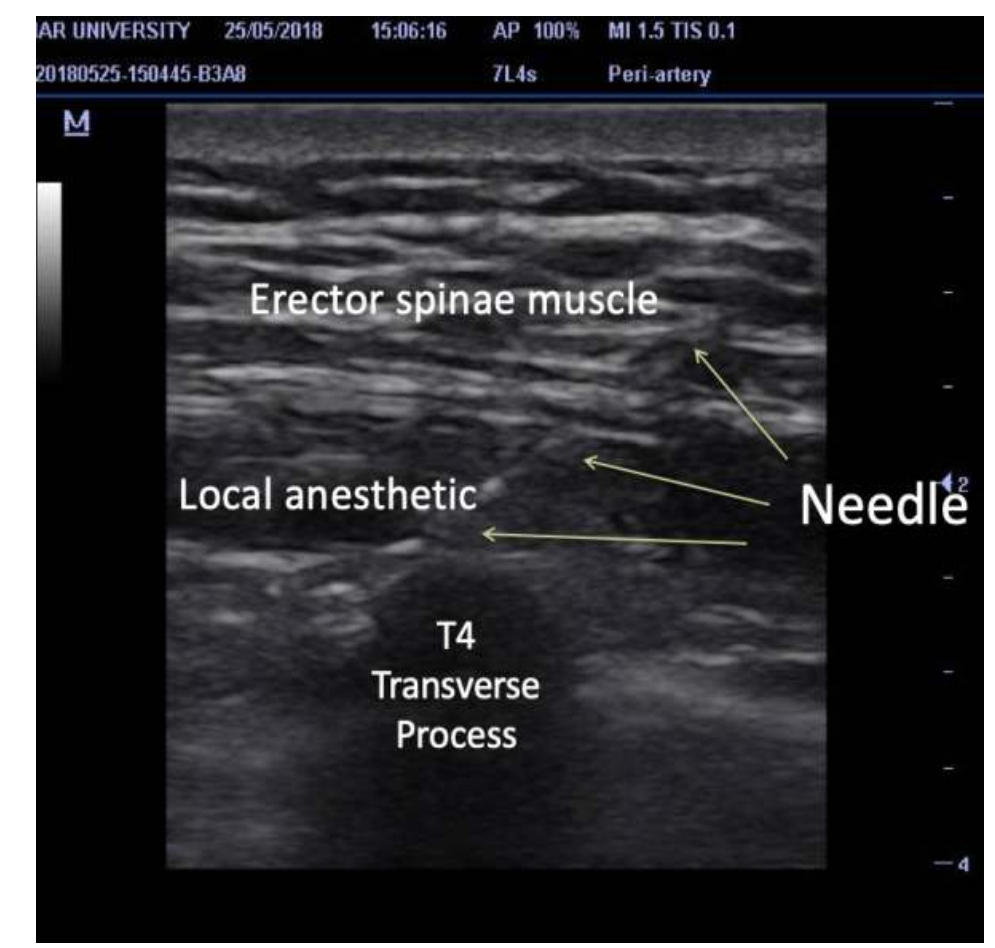

Figure2
Results: After 20 minutes, we checked the operation site with pinprick test and confirmed complete sensorial loss to pain at the surgical site. The operation started uneventfully and lasted for 40 minutes. The patient was comfortable during the operation and there was no need for additional sedatives or analgesics (Figure 3).

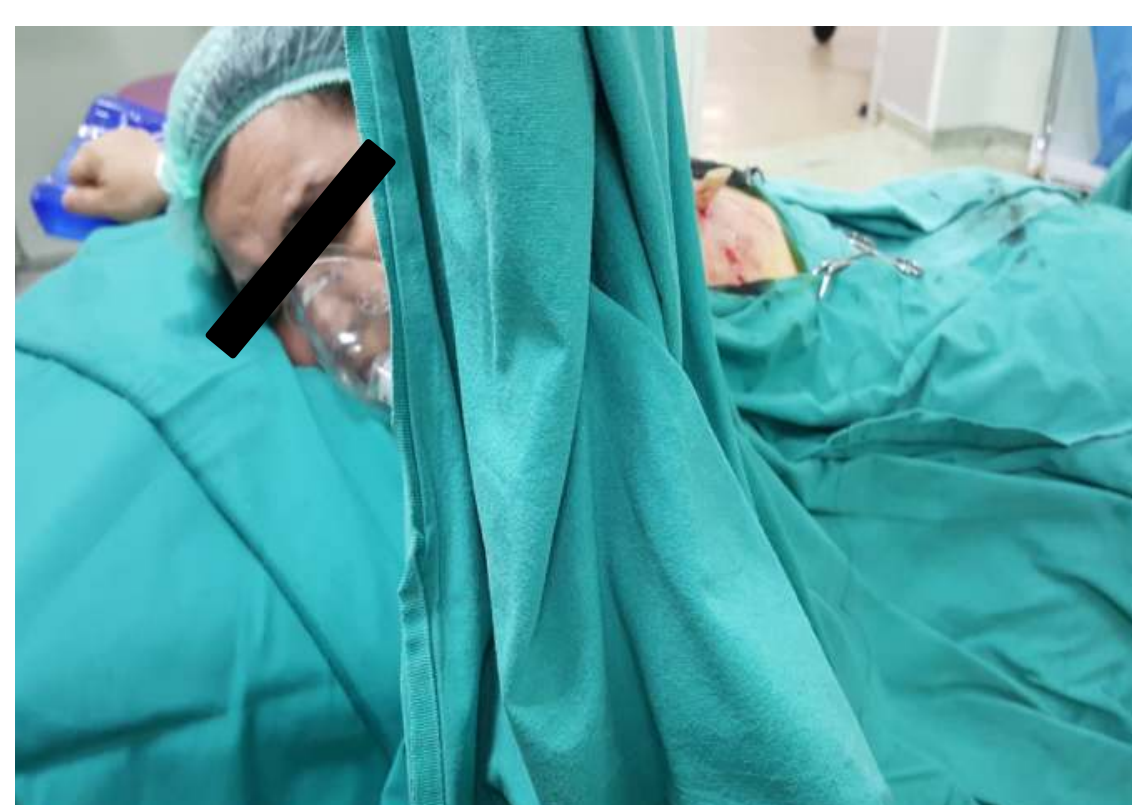

Figure 3

$12 \mathrm{~cm}$ transverse incision was performed and $6 \times 6 \mathrm{~cm}$ lipoma was excised (Figure 4).

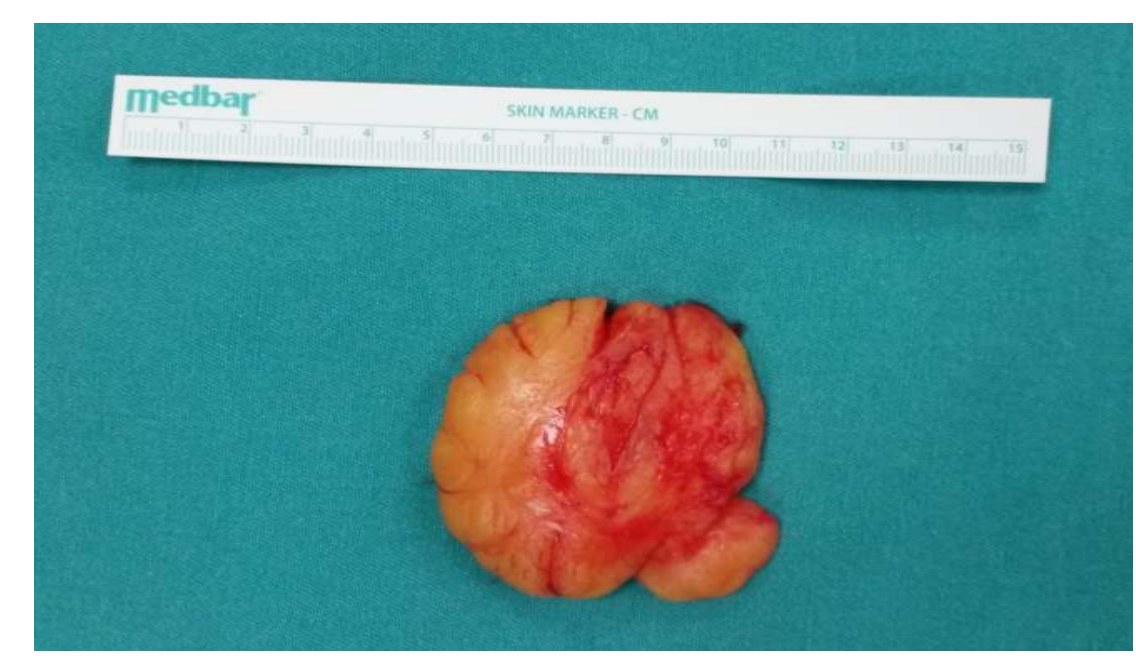

Figure 4

Conclusion: Our case demonstrated that sufficient surgical anesthesia at posterior thoracic region is possible with performance of ESP block. In our case, possible risks of general anesthesia and endotracheal intubation have been avoided and the patient was discharged on the same day without additional analgesic requirement.

1. Kimachi PP, Martins EG, Peng P, Forero M. The Erector Spinae Plane Block Provides Complete Surgical Anesthesia in Breast Surgery: A Case Report. A A Pract. 2018 Apr 23.

2. Ahiskalioglu A, Yayik AM, Celik EC, Ahiskalioglu EO, Emsen M. Two plane two block for surgical anesthesia: ultrasound-guided serratus and erector spinae plane blocks. J Clin Anesth. 2018;47:19-20.

3. Balaban O Aydin T, Yaman M. Is ultrasound guided erector spinae plane block sufficient for surgical anesthesia in minor surgery at thoracal region? J Clin Anesth. 2018;47:7-8.

4. Tulgar S, Thomas DT, Deveci U. Erector spinae plane block provides sufficient surgical anesthesia for ileostomy closure in a high-risk patient. J Clin Anesth. 2018;48:2-3 